Seismic Moment Tensor Report for the 06 Aug 2007, M3.9 Seismic Event in Central Utah

S. R. Ford, D. S. Dreger, W. R. Walter, M. Hellweg, R. Urhammer

August 16, 2007 
This document was prepared as an account of work sponsored by an agency of the United States Government. Neither the United States Government nor the University of California nor any of their employees, makes any warranty, express or implied, or assumes any legal liability or responsibility for the accuracy, completeness, or usefulness of any information, apparatus, product, or process disclosed, or represents that its use would not infringe privately owned rights. Reference herein to any specific commercial product, process, or service by trade name, trademark, manufacturer, or otherwise, does not necessarily constitute or imply its endorsement, recommendation, or favoring by the United States Government or the University of California. The views and opinions of authors expressed herein do not necessarily state or reflect those of the United States Government or the University of California, and shall not be used for advertising or product endorsement purposes.

This work was performed under the auspices of the U.S. Department of Energy by University of California, Lawrence Livermore National Laboratory under Contract W-7405-Eng-48. 


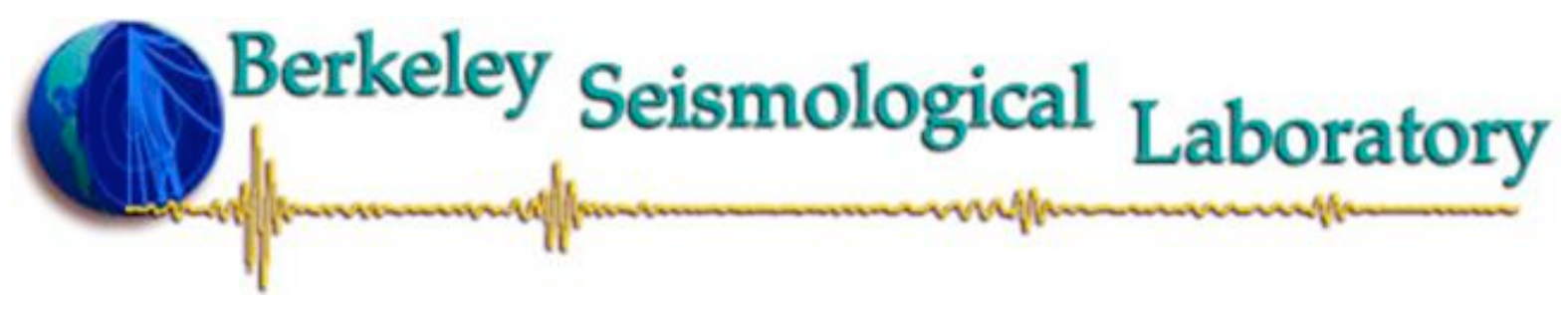

\title{
Seismic Moment Tensor Report for the 06 Aug 2007, M3.9 Seismic event in central Utah
}

\author{
Prepared by: Sean Ford ${ }^{1,2}$, Douglas Dreger ${ }^{1}$, William Walter ${ }^{3}$, Margaret Hellweg ${ }^{1}$ and Robert \\ Uhrhammer $^{1}$ \\ 1. Berkeley Seismological Laboratory \\ 2. Summer Intern at the Lawrence Livermore National Laboratory \\ 3. Lawrence Livermore National Laboratory
}

Last Updated: August 11, 2007

\section{Summary}

We have performed a complete moment tensor analysis (Minson and Dreger, 2007) of the seismic event, which occurred on Monday August 6, 2007 at 08:48:40 UTC, $21 \mathrm{~km}$ from Mount Pleasant, Utah. The purpose of this report is to present our scientific results, making them available to other researchers working on seismic source determination problems, and source type identification. In our analysis we used complete, three-component seismic records recorded by stations operated by the USGS, the University of Utah and EarthScope. The results of our analysis show that most of the seismic wave energy is consistent with an underground collapse, however the cause of the mine collapse is still unknown.

\section{Analysis Method}

The broadband stations from the USGS, the University of Utah and EarthScope's USArray networks provide excellent azimuthal coverage of the event. In Figure 1 we show the positions of 16 stations with good signal to noise levels along with the location of event. We pre-processed the waveform data by deconvolving the instrument response, integrating the records to ground displacement, and filtering between 0.02 to $0.10 \mathrm{~Hz}$. The Song et al. (1996) velocity model was used to compute the Green's functions used in the moment tensor inversion. 


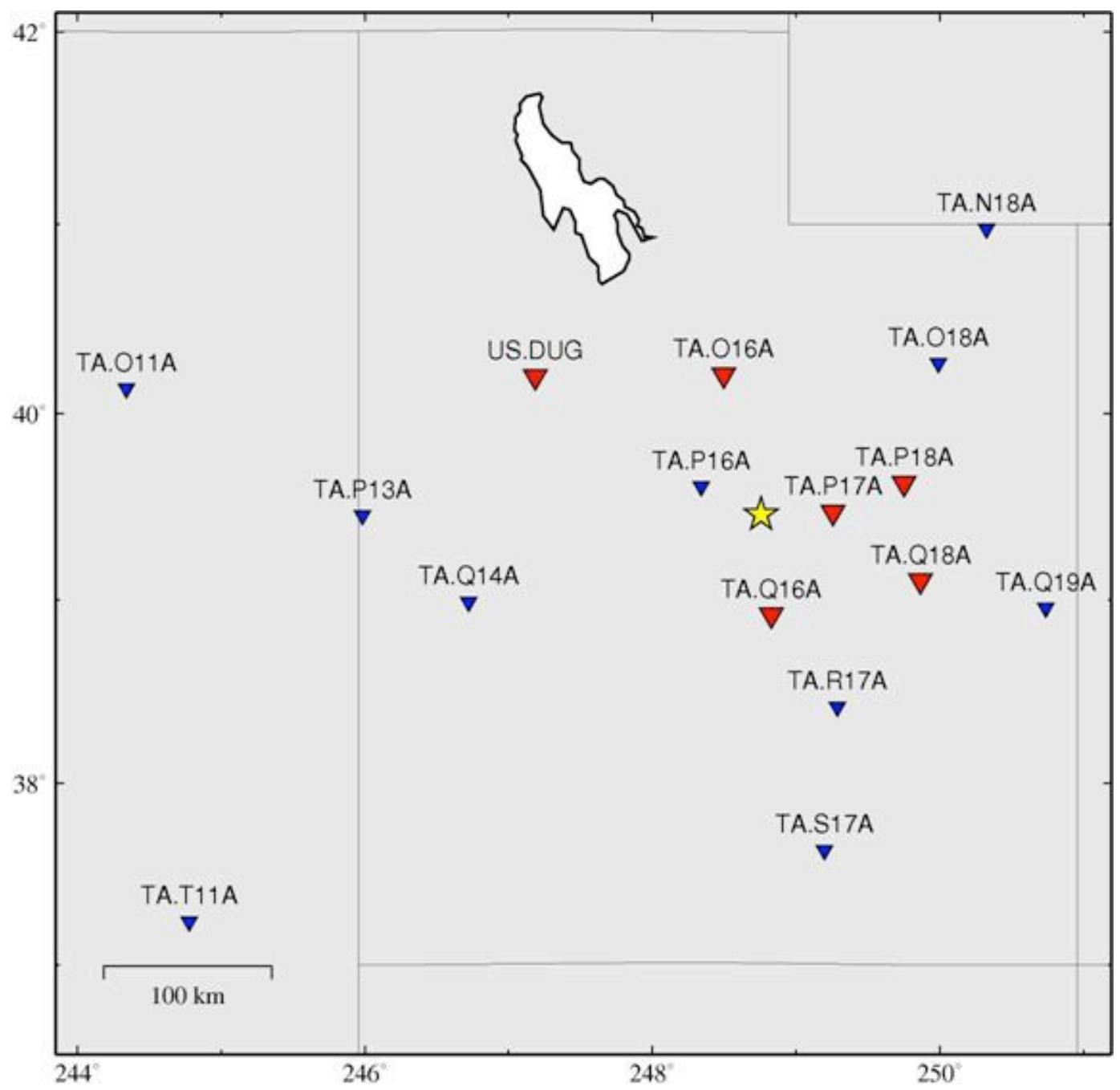

Figure 1. Map with the event location (yellow star) and stations used (triangles). Data from both the red and blue stations were used in Figure 2. The red triangles are the stations closest to the event used for the inversion shown in Figure 3.

For the moment tensor analysis we assumed a source depth of $1 \mathrm{~km}$, consistent with the shallow depth reported for this event. As shown in Figure 2 the results using all 16 stations show a source mechanism with negligible double-couple radiation. It is dominated by CLVD and implosive isotropic elements. In contrast a typical earthquake has a moment tensor solution that is dominated by the double-couple component.

The total scalar seismic moment in this solution is $1.92 \times 10^{22}$ dyne-cm, corresponding to a moment magnitude $(\mathrm{Mw})$ of 4.2. The long-period records are very well matched by the model (Figure 2) with an overall variance reduction of $54.1 \%$. The moment tensor solution predicts that the radiation pattern will have dilational (down) first motion in all directions, or in other words a "beachball diagram" that is all white. The nearest stations have better signal to noise levels, and in Figure 3 we show a solution obtained with 6 of the best stations. The two solutions are in agreement, and as the shown the fit to the data is very good quantified by a $74.1 \%$ variance reduction. 
See http:/quake.wr.usgs.gov/recenteqs/beachball.htm for a tutorial on "beachball diagrams" and how they can relate to tectonic earthquakes. See http://seismo.berkeley.edu/ dreger/fmexample.gif for an example of first motions for a tectonic earthquake. Note that neither the preferred full moment tensor solution for the Utah event nor the first motions, as shown below, show the alternating P-wave first motion polarity pattern which is a characteristic of tectonic earthquakes.

See Appendix A below for an example of a moment tensor inversion of a Mw4.4 earthquake that occurred near Alder Montana.
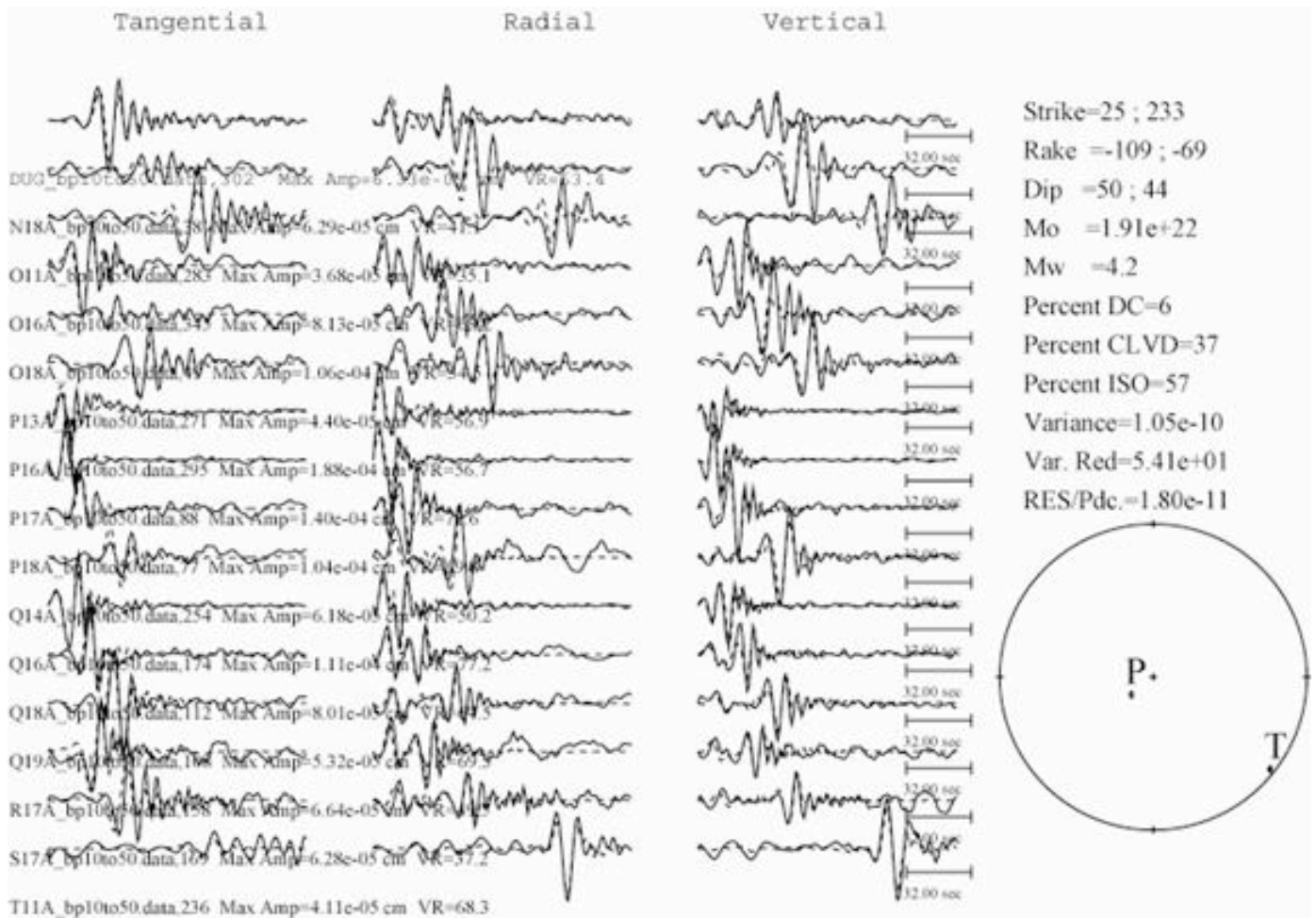

Figure 2. Moment tensor solution using 16 regional stations. The observations are solid lines and the synthetic seismograms are dashed. The $\mathrm{P}$ wave radiation pattern, or "beachball diagram" is plotted together with the orientation of the compressive axis. In the moment tensor mechanism, white areas indicate a dilatational, or down P-wave first motion. Since this mechanism is all white, all first arriving P-waves would be expected to be dilatational. 


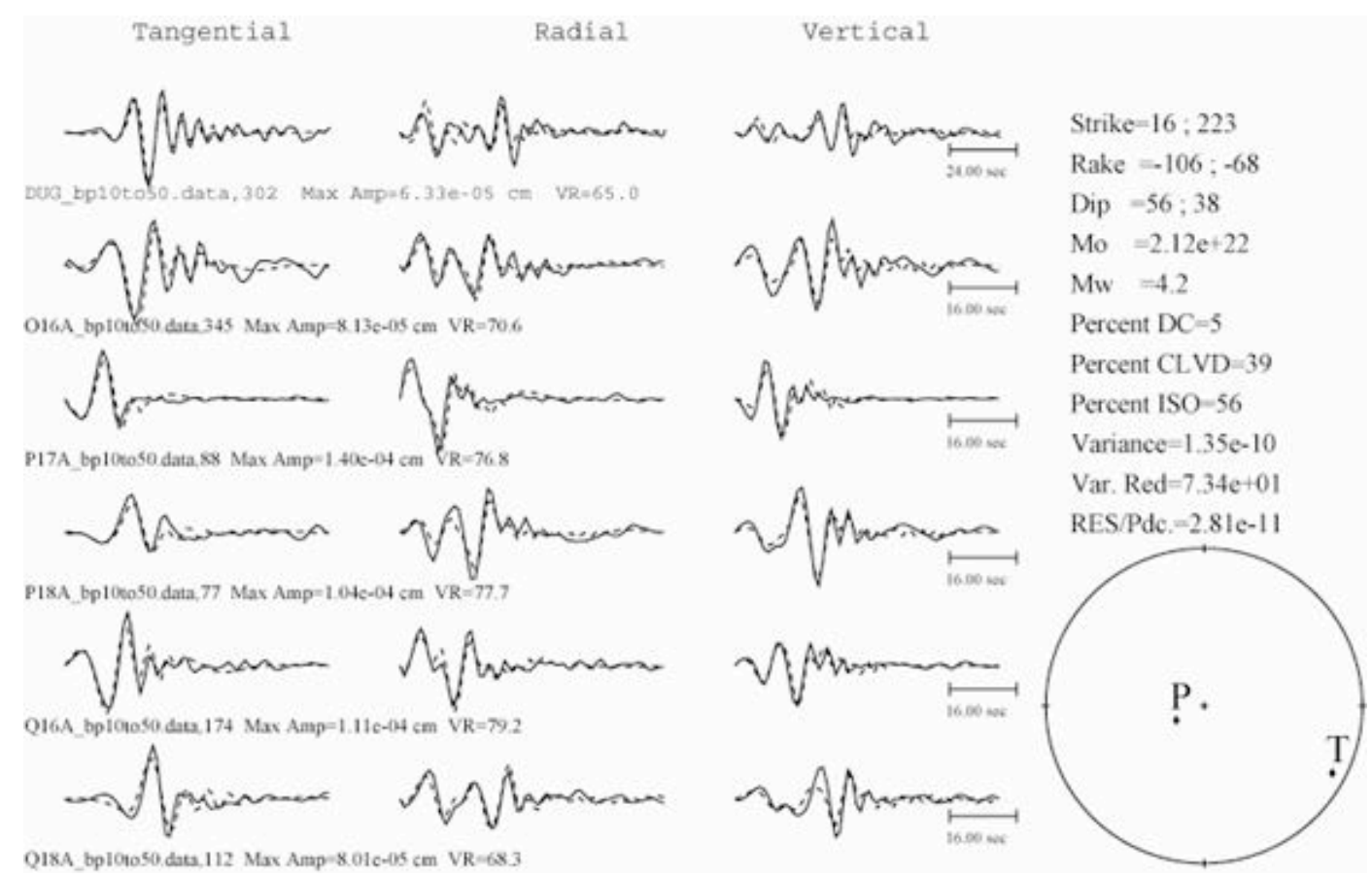

Figure 3. Same as Figure 2 using six nearby stations with excellent signal to noise levels (red stations in Figure 1).

To illustrate why we feel the full moment tensor solution shown in Figures 2 and 3 is correct, we compare a deviatoric moment tensor inversion in Figure 4. A deviatoric inversion does not allow for a volumetric source. The fit to the data is visibly worse. While the transverse component records are fit well in some cases, it is not possible to fit the transverse and radial/vertical components simultaneously. In fact, the variance reduction in this case is significantly worse at only $41.8 \%$ more than $30 \%$ lower than the preferred solution shown in Figure 3. The P-wave first motion radiation pattern for the deviatoric solution, its "beachball diagram", is substantially different than that in Figures 2 and 3, having a dominant double-couple component that shows steep dip-slip faulting. This radiation pattern is not consistent with the observed first motions. 


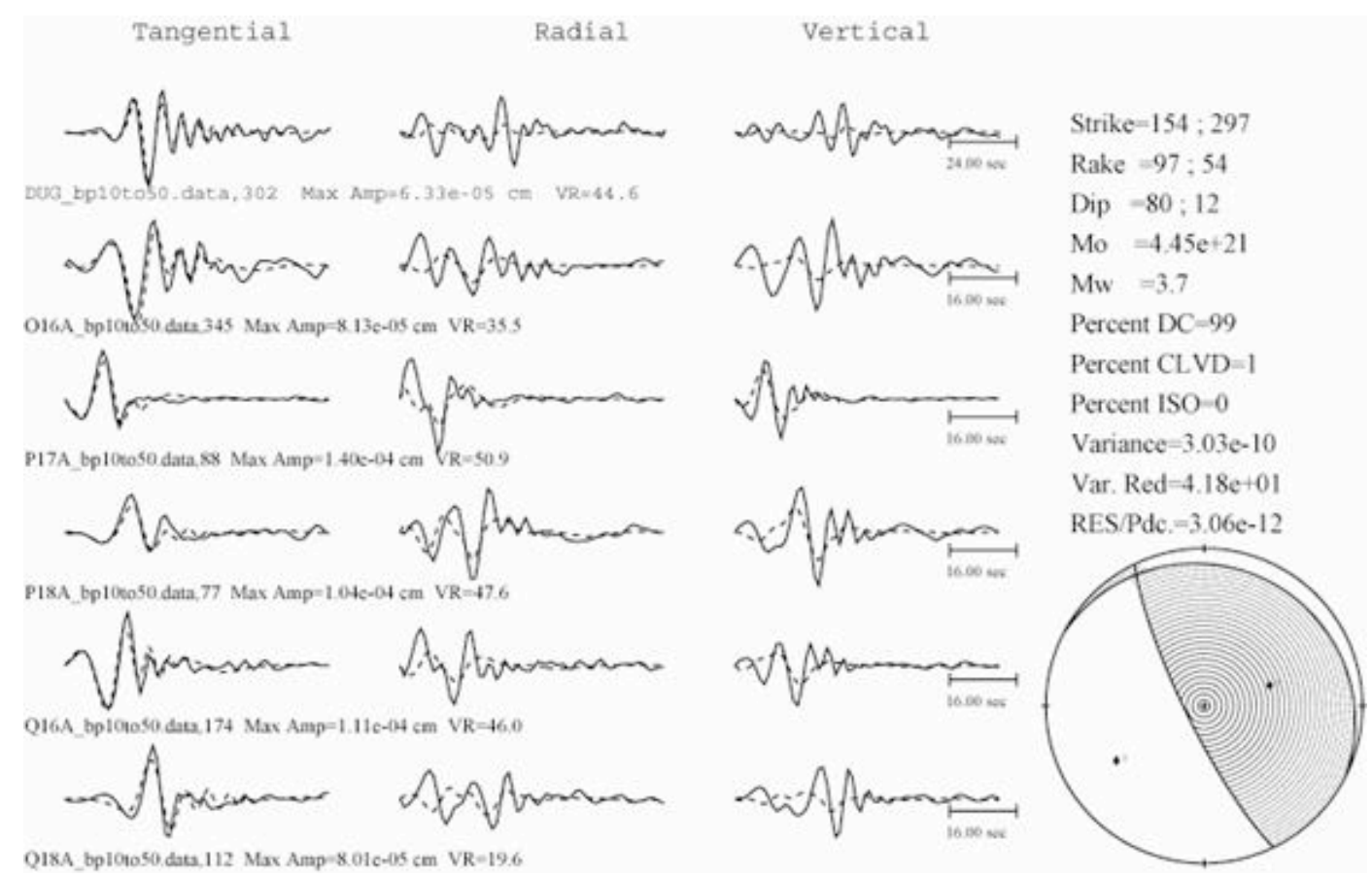

Figure 4. Deviatoric moment tensor solution using the same stations in Figure 3. Note that the fit of the data is significantly worse than in Figure 3

P-wave first motion polarities provide further confirmation of the preferred mechanism. The P-wave polarities are all down indicating dilational initial motions. In Figure 5 first-motions picked by Professor Pechmann of the University of Utah are superimposed on the the preferred mechanism from Figure 3 and the deviatoric mechanism (Figure 4). It is clear that the deviatoric moment tensor solution (Figure $5 b)$ does not agree with the first motion polarities. On the other hand, the preferred full moment tensor solution (Figure 5a) does satisfy the first motion polarities. To see an example of first motions for a tectonic earthquake see http://seismo.berkeley.edu/ dreger/fmexample.gif.

The conclusion drawn from this analysis is that the source mechanism obtained using shallow (1 km Greens functions) and allowing volume to change at the source (Figures 2 and 3 ) is consistent with the collapse of an underground cavity. 

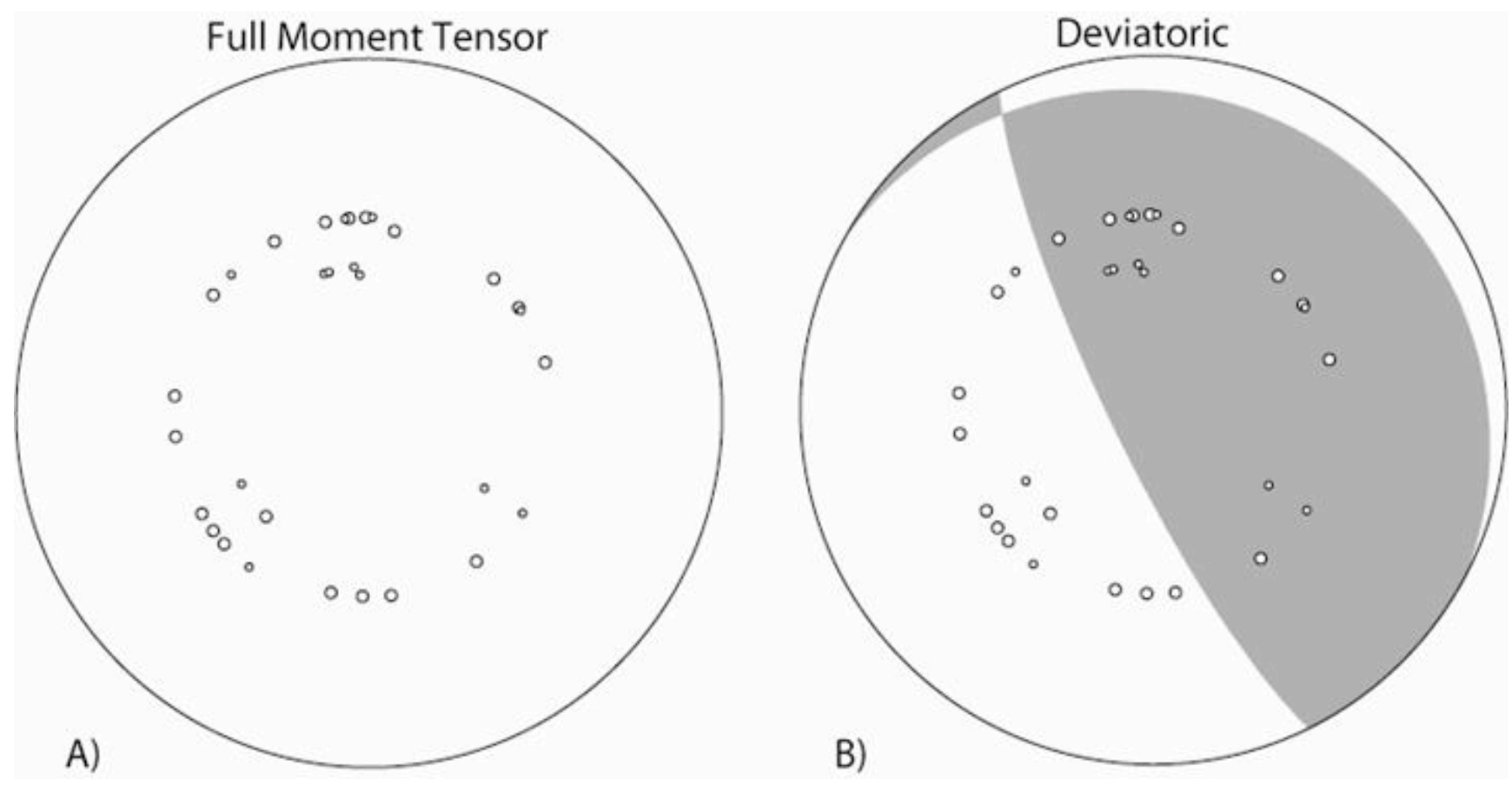

Figure 5. First-motions picked by Professor Pechmann of the University of Utah are compared to A) the full moment tensor solution (Figure 3) and the B) deviatoric moment tensor solution (Figure 4). Filled symbols would indicate compressional arrivals (none were observed), and open circles indicate dilation. The first motion measurements are obviously more consistent with the preferred inversion result using the full moment tensor solution which allows volumetric change a the source.

The source type plot of Bowers and Hudson (1999) is useful for identifying the mechanism of the source from a general full moment tensor inversion. In this type of plot, shown in Figure 6, a measure of the volumetric moment is compared with the degree of double-couple. Regions of this plot relate to the possible sources that can be decomposed from a general moment tensor such as a double-coupled (DC, typical tectonic earthquake), a compensated linear-vector dipoles (CLVD), dipoles, explosions or implosions, and cracks. The sign on the x-axis, which passes through the origin, which is a DC defines whether the major vector dipole of the solution points outward (positive) indicating opening or inward (negative) indicating closing. Tectonic earthquakes appear close to the origin in such plots. The solution that we obtained for the Utah event plots in the region defining a negative crack, or anti-crack, which represents the process of collapse of an underground cavity (Pechmann et al., 1995; Bowers and Walter, 2002). 


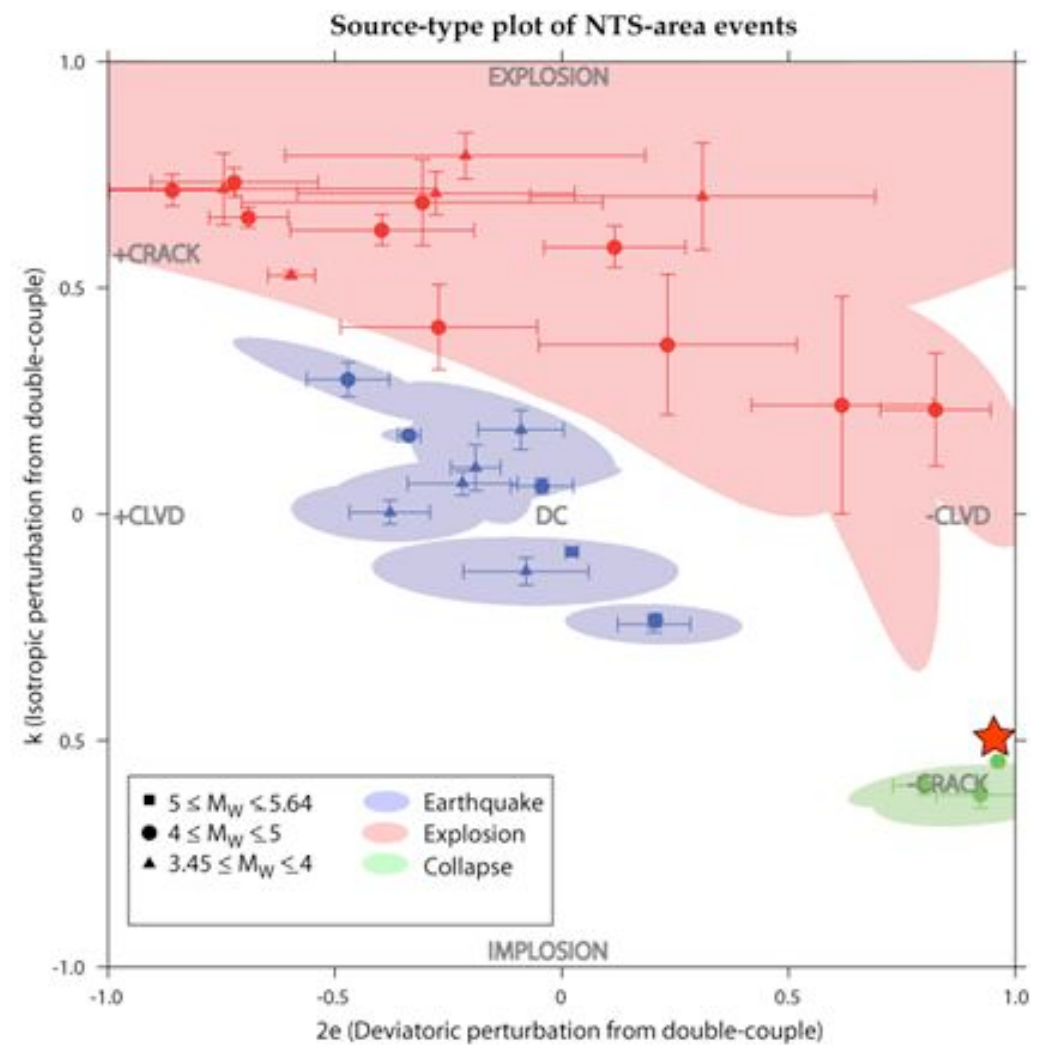

Figure 6. Source type plot based on Bowers and Hudson (1999). In this plot earthquake, explosion and collapse data from Ford et al. (2007) is compared to the August $6^{\text {th }}$ event (red star). The August $6^{\text {th }}$ event plots in the general moment tensor space that defines an closing crack, or collapse. The event is located well outside the region occupied by tectonic earthquakes.

Analysis of the sensitivity of the moment tensor solution to source depth indicates that shallow depths are preferred (Figure 7a). In this analysis 19 stations were used. The data was processed as described above. Depths of $600 \mathrm{~m}, 800 \mathrm{~m}$ and $1 \mathrm{~km}$ give similar levels of fit. The slight increase in fit from 2 to 3 $\mathrm{km}$ depth is likely due to the presence of a velocity discontinuity in the structure modeled used to compute the Green's functions. Another very interesting result is that the moment tensor solution remains stable and strongly crack-like over the depth range from $600 \mathrm{~m}$ to $5 \mathrm{~km}$ (Figure $7 \mathrm{~b}$ ). Assumed sources at greater than $5 \mathrm{~km}$ depth become less crack-like, but also remain substantially different from a double-couple. 


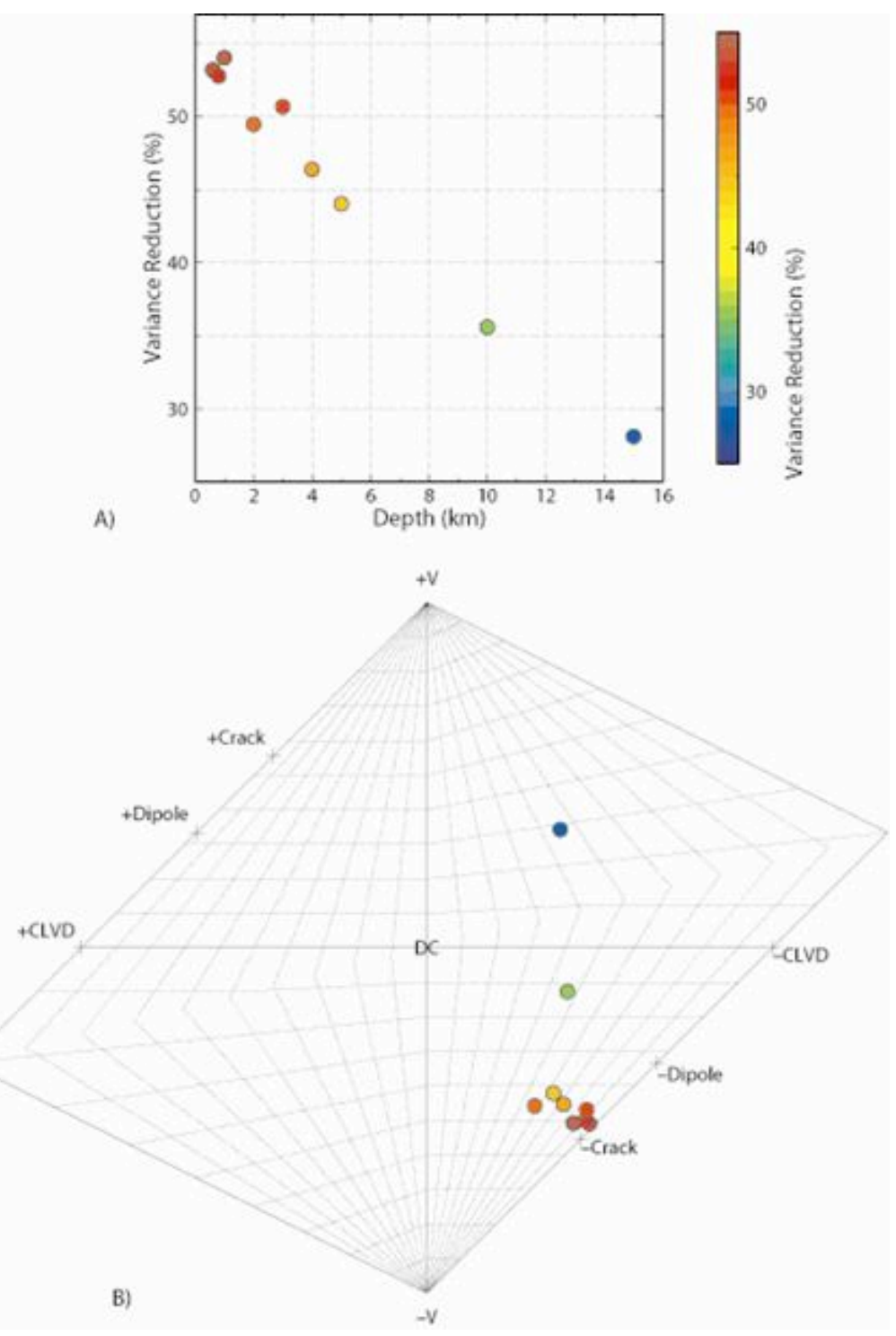

\section{Acknowledgements}

S.F.'s summer internship at LLNL is supported by the joint project between William R. Walter at LLNL and Doug Dreger at UCB under Department of Energy BAA contract DE-FC52-06NA27324. This work was performed in part under the auspices of the U.S. Department of Energy by University of California, Lawrence Livermore National Laboratory under Contract W-7405-Eng-48. This is LLNL contribution UCRL-TR-233539-DRAFT. We acknowledge Ralph Falk for his assistance with our P-wave first motion analysis, and Professors Pankow and Pechmann for providing their first motion data.

\section{References}

Bowers, D., and W. Walter (2002). Discriminating between large mine collapses and explosions using teleseismic $\mathrm{P}$ waves, PAGEOPH, 803-830.

Dreger, D. and B. Woods (2002). Regional distance seismic moment tensors of nuclear explosions; seismic source mechanism through moment tensors, Tectonophysics, 356(1-3), 139-156. 
Pechmann, J. C., W. R. Walter, S. J. Nava, and W. J. Arabasz (1995). The February 3, 1995 ML 5.1 seismic event in the trona mining district of southwestern Wyoming, Seism. Res. Lett., 66, 25-34.

Sean R. Ford, Douglas S. Dreger, and William R. Walter (2007) IDENTIFYING ISOTROPIC

EVENTS USING AN IMPROVED REGIONAL MOMENT TENSOR INVERSION

TECHNIQUE, Monitoring Research Review, Denver, CO.

Minson, S. and D. Dreger (2007). Improved seismic moment tensor inversion, Geophys J. Int. .

Song, X. J., D. V. Helmberger and L. Zhao (1996). Broad-band modelling of regional seismograms; the basin and range crustal structure, Geophys. J. Int., 125(1), 15-29.

\section{Appendix A - Example of the Moment Tensor Inversion of the May 8, 2007 Alder Montana event}

On May 8, 2007 a Mw4.4 event occurred near Alder Montana. This event was well recorded by 149 stations operated by several organizations (Figure A1). We used the data in the same way described above to determine the moment tensor of this event. The results shown in Figure A2 indicate the event is best characterized as a double-couple. The fit to the deviatoric (non-volumetric) source is $80 \%$. Allowing a volumetric component increases the fit by $89 \%$ and introduces a small isotropic component. Both the deviatoric and full moment tensor models provide excellent fit to the data due to the dominant double-couple component in contrast to the case for the August 6 event.

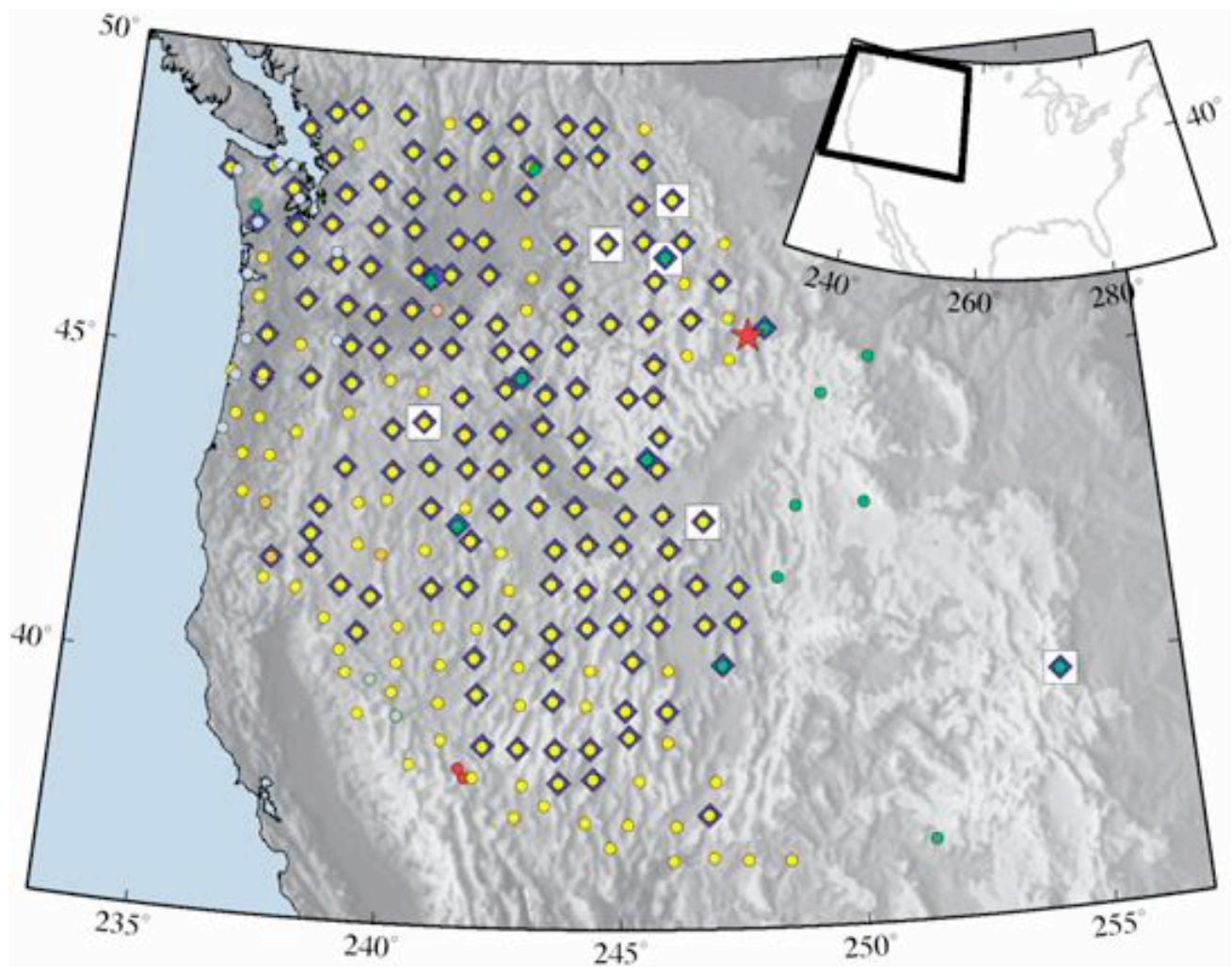

Figure A1. Location of 8 May 07 event near Alder, MT (red star) and stations used in the MT analysis (blue diamonds) along with those used in the subset analysis (white square). All stations $\sim 1000 \mathrm{~km}$ from the event are shown (small circles), where the networks are TA (yellow), BK (orange), IM (red), IU (light orange), US (green), UW (light blue). Inset, location 
on continental US.

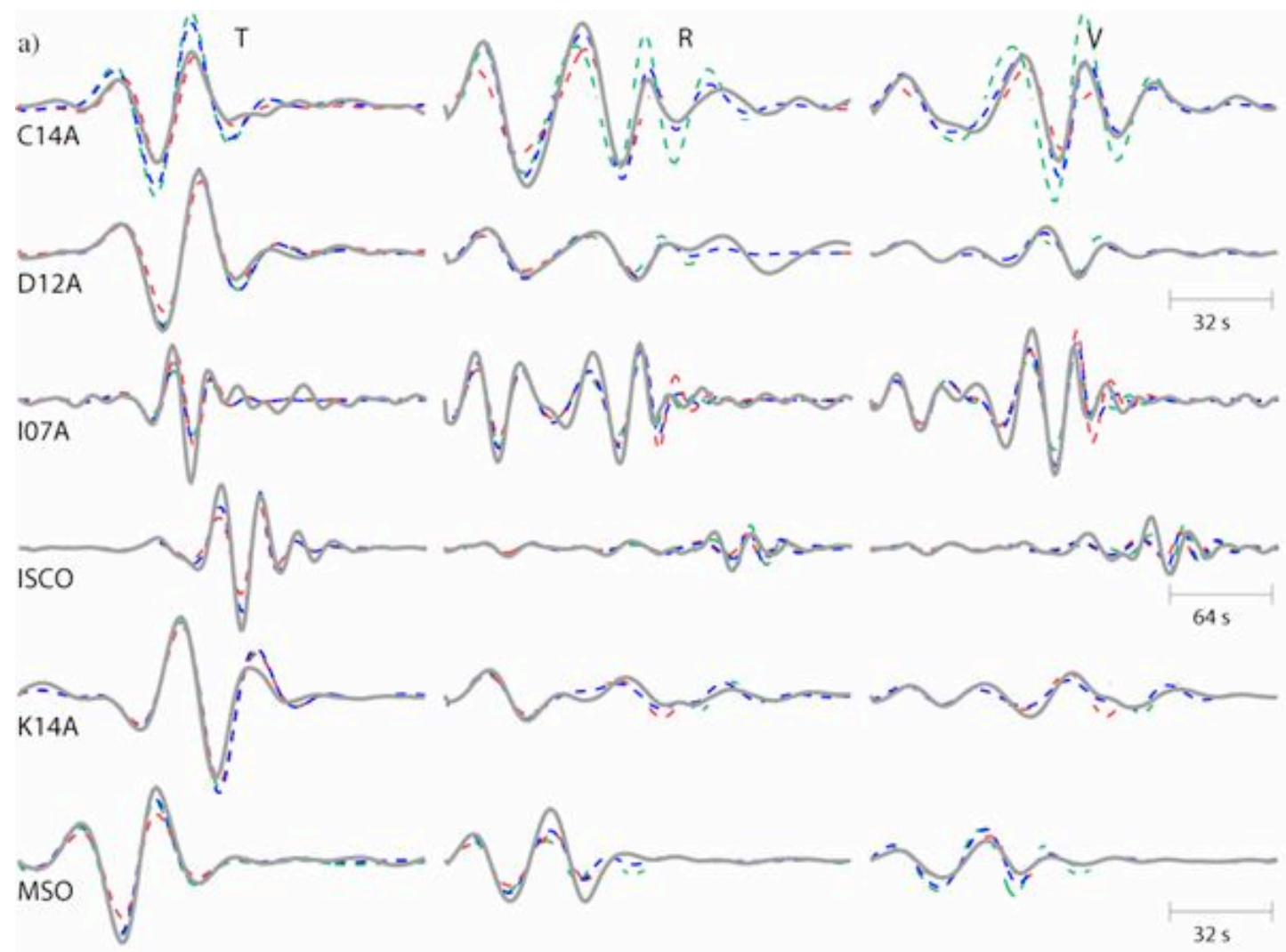

b) Deviatoric 6-station (VR=80\%)

c) Full 6-station $(\mathrm{VR}=89 \%)$

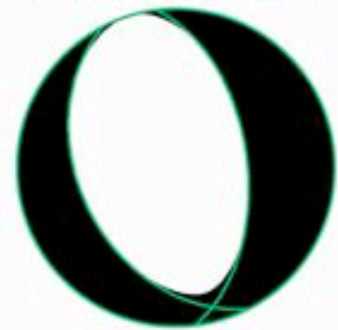

$\mathrm{M}_{0}=4.87 \times 10^{22} \quad \mathrm{M}_{\mathrm{w}}=4.39$

Strike Rake Dip $351,151 \quad-77,-106 \quad 51,40$

Strike Rake Dip $351,148 \quad-75,-108 \quad 52,41$

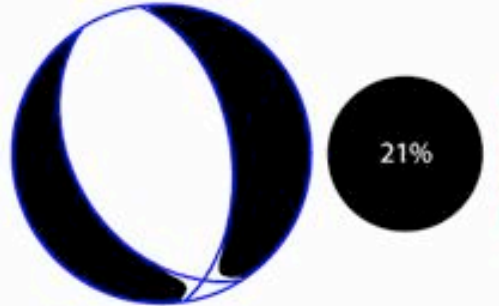

d) Full 149-station (VR=55\%)

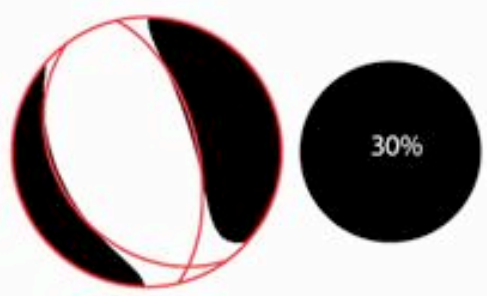

$\mathrm{M}_{0}=5.44 \times 10^{22} \quad \mathrm{M}_{\mathrm{W}}=4.43$

$\mathrm{M}_{0}=5.85 \times 10^{22} \quad \mathrm{M}_{\mathrm{W}}=4.45$
Strike Rake Dip $347,144 \quad-78,-110 \quad 59,33$

Figure A2. a) Data (grey) and synthetics predicted by the solution using 149 stations (red) and 6 stations with an even azimuthal distribution for a deviatoric solution (green) and full solution (blue). b) Deviatoric focal mechanism where area is scaled by $M_{0}$, and source parameters for the 6-station solution c) Deviatoric and isotropic component (with $M_{0} \%$ ), for the 6-station solution. c) Deviatoric focal mechanism and isotropic component for the 149 -station solution. VR in title is the \% variance reduction, a goodness of fit measure. 